\title{
Development of an Assessment Tool for Domestic Elder Abuse: Creation of Items from a Literature Review
}

\author{
Qinqiuzi Yi, Junko Honda, Naohiro Hohashi* \\ Division of Family Health Care Nursing, Department of Nursing, Graduate School of Health Sciences, Kobe \\ University, Hyogo, Japan \\ Email: "naohiro@hohashi.org
}

Received 9 October 2015; accepted 9 November 2015; published 13 November 2015

Copyright (C) 2015 by authors and Scientific Research Publishing Inc.

This work is licensed under the Creative Commons Attribution International License (CC BY). http://creativecommons.org/licenses/by/4.0/

(c) (i) Open Access

\section{Abstract}

Background: With the "super-aging" of society, the prevalence of elder abuse can be expected to come under greater scrutiny. It will be important, therefore, to evaluate the presence and severity of elder abuse so as to prevent abuse and provide greater support for families. Aim: The aim of this study is to identify acts of elder abuse from a literature review in order to develop items for an assessment tool for domestic elder abuse. Methods: For the literature search, ICHUSHI Web, China National Knowledge Infrastructure (CNKI), and PubMed were utilized with the keywords "elder abuse" and "elderly abuse". A search limited to original articles over the last five years containing descriptions of elder abuse was used in this study. In addition, through hand search, books and websites concerning elder abuse were also studied. Descriptions of the acts of elder abuse from the materials were extracted and categorized by content analysis based on seven subtypes of elder abuse (physical abuse, neglect, psychological abuse, sexual abuse, economical abuse, selfneglect, and social abuse). Results \& Conclusions: The final analysis included 18 original articles, two books, and eight websites on elder abuse prevention. A total of 38 acts were extracted as items for the assessment tool, which can be used to evaluate the presence and severity of elder abuse. Further research will be needed to examine the validity and reliability of the assessment tool.

\section{Keywords}

Domestic Elder Abuse, Assessment Tool, Literature Review

\footnotetext{
${ }^{*}$ Corresponding author.
}

How to cite this paper: Yi, Q., Honda, J. and Hohashi, N. (2015) Development of an Assessment Tool for Domestic Elder Abuse: Creation of Items from a Literature Review. Advances in Aging Research, 4, 195-204. 


\section{Introduction}

As the number of elderly persons grows because of the rise in the average lifespan, a variety of issues and challenges concerning elder care have been discussed in Japan. Among those, elder abuse has attracted a great deal of attention. However, despite the enactment of the "Elder Abuse Prevention Law" (Act on the Prevention of Elder Abuse, Support for Caregivers of Elderly Persons and Other Related Matters) in 2006, the number of complaints and incidents reported on elder abuse has continued to rise, according to the results of the latest nationwide survey conducted by the Ministry of Health, Labour and Welfare [1].

As in Japan, with the development of economic and medical technology, the elderly population in China has been rapidly increasing and elder abuse is also coming to be viewed as a problem in China. Based on the Office for National Statistics' survey in December 2010, the incidence of elder abuse in China was 13.3\%, and the prevalence of elder mistreatment was $35.2 \%$ in the urban areas of Nanjing City [2] and 36.2\% in the rural areas of Hubei Province [3]. However, in China, which is said to be "age before it gets rich", the elder abuse issue is much less recognized as a social problem; and the actual prevalence of elder abuse may be much higher than the published data indicate because the medical, health, and welfare systems are still undeveloped. Therefore, in both China and Japan, it is important to obtain a better grasp of the state of elder abuse and provide adequate support where warranted.

To support the prevention of elder abuse as a basic premise, it is essential to assess whether or not elder abuse is present. With this aim, several kinds of excellent screening and assessment instruments, such as the Vulnerability to Abuse Screening Scale [4] and the Elder Assessment Instrument [5], have been developed through rigorous research or by the elder abuse prevention agency. However, as noted by Umezaki, elder abuse is a social issue, and countermeasures and policies should be discussed in terms of their social and cultural environments [6]. For this reason, assessment tools for elder abuse that were developed in the context of Western culture may not be suitable for use within an Asian culture owing to pronounced cultural differences [7]. Moreover, not only is it important to assess whether or not the abuse exists, but also assess severity when it does exist, so that the situation can be remedied, enabling the abused elderly person to receive proper care. However, among the commonly used instruments, with the exception of the Indicators of Abuse [8], almost no instrument has been developed through rigorous research that can grasp the severity of the abuse. Therefore, it is necessary to develop a tool to assess both the presence and the severity of elder abuse that is consistent with the social and cultural norms of China and Japan.

From the above, the purpose of this study was to extract acts of elder abuse from a literature review to develop items for an assessment tool that evaluates the presence and the severity of elder abuse.

\section{Methods}

\subsection{Definitions of Elder Abuse}

This review focused on domestic elder abuse, which is operationally defined as "elder abuse by a caregiver", as opposed to "elder abuse by a care facility staff member, etc.”. According to the Elder Abuse Prevention Law enacted in April 2006, the term "elderly person" means a person who is 65 years of age or older, and the term "caregiver" means a person who actually takes care of an elderly person and does not fall under the category of a care facility staff member, and others [9].

In this review, in addition to the subtypes of elder abuse defined by the Elder Abuse Prevention Law (i.e., physical abuse, neglect, psychological abuse, sexual abuse, and economical abuse), self-neglect and social abuse were included as subtypes, in view of the protection of the human rights of elderly persons, because a variety of social relationships that the elderly person has cultivated in his/her life seriously affect his/her energy to live and sense of mental relief. Therefore, elder abuse in this study is defined as an act that falls under any of the following subtypes (1 - 7):

1) Physical Abuse

Inflicting an assault upon an elderly person that will cause or is likely to cause external harm to his/her body.

2) Neglect

Substantially failing to take care of an elderly person, including severely depriving the elderly person of food or leaving him/her unattended for a long period of time in a manner that would likely cause his/her health to deteriorate; and also including disregard of acts inflicted by any person who lives with the elderly person but who 
does not fall under the category of a caregiver.

3) Psychological Abuse

Directing to an elderly person any words or deeds that would likely be significantly traumatic to him/her, including significantly abusive language or a significantly negative attitude toward him/her.

4) Sexual Abuse

Committing an indecent act against an elderly person, or making an elderly person engage in such an act.

5) Economic Abuse

The unjust disposal of an elderly person's property by a caregiver or relative, or any other unjust acquisition of property from an elderly person.

6) Self-Neglect

Falling into a state that will endanger the elderly person's safety and health, due either to refusal or inability to perform actions that would normally be carried out in life by the elderly person himself/herself [10].

7) Social Abuse

Cutting off the elderly person's social contact with others, or restricting the elderly person's social activities to socially isolate him/her, making him/her feel socially excluded.

\subsection{Data Collection}

In May 2014, we conducted a search of Ichushi Web, China National Knowledge Infrastructure (CNKI), and PubMed with the keywords "elder abuse" and "elderly abuse”. The search was limited to original articles published over the previous five years written in Japanese, Chinese, and English. The titles and abstracts of the original articles identified by the search were screened with the aim of excluding papers that focused on the care of elderly persons, examined the effects of elder abuse prevention/support programs, and/or reviewed the works and roles of the professions who are working in the elder abuse field. Through this screening procedure, 61 articles were perused to identify whether they contained descriptions about acts of elder abuse. This process resulted in 18 articles that were used for the study. In addition, through a hand search, books on elder abuse and websites on elder abuse prevention containing descriptions about acts of elder abuse were also studied.

\subsection{Analysis}

From the collected material, the descriptions of the acts of elder abuse were extracted and classified into the seven subtypes of elder abuse (i.e., physical abuse, neglect, psychological abuse, sexual abuse, economic abuse, self-neglect, and social abuse). Moreover, content analysis was used to analyze the data and the data were categorized according to the similarity of the contents.

To ensure rigor, the analytic process of categorization continued until agreement was obtained among three researchers. Inclusion criteria for the content analysis were: 1 ) specific examples cited in the definition of elder abuse; 2) descriptions of the acts of elder abuse experienced by an elderly person in the original articles; 3) acts of elder abuse described in questionnaires used to investigate elder abuse; and 4) acts of elder abuse contained in an elder abuse checklist. Exclusion criteria were mental and physical signs of the elderly person as items for screening elder abuse.

\section{Result}

\subsection{Source of the Collected Materials}

An overview of the collected materials is shown in Table 1. Among the 18 original articles, 10 were published in Japanese, five in Chinese, and three in English. In addition, through hand searches, two books (one in Japanese, one in English), three Japanese government reports, and five websites on elder abuse were used in the present review.

\subsection{Acts of Elder Abuse}

The acts of elder abuse that were analyzed and categorized based on the seven subtypes of elder abuse are presented in Table 2.

Regarding acts of physical abuse, in addition to "subjected to physical violence" that is an act of direct violence to the elderly person, acts such as tying the elderly person to the bed and inappropriate use of drugs to 
Table 1. Source of the collected materials $(n=28)$.

\begin{tabular}{|c|c|c|c|}
\hline Country & Original papers $(\mathrm{n}=18)$ & Websites $(\mathrm{n}=8)$ & Books $(\mathrm{n}=2)$ \\
\hline & $\begin{array}{l}\text { Matsuyama, M., Morita, N. and Ogai, Y. (2013) Mental } \\
\text { Health of Parents of the Mentally Disabled and its } \\
\text { Related Factors: Focusing on Parent Abuse by the } \\
\text { Mentally Disabled Children. Japanese Journal of } \\
\text { Addiction \& Family, 29, 50-59. }\end{array}$ & $\begin{array}{l}\text { Ministry of Health, Labour and } \\
\text { Welfare.The Basics of Elder Abuse } \\
\text { Prevention. } \\
\text { http://www.mhlw.go.jp/topics/kaigo/bous } \\
\text { hi/060424/dl/02.pdf }\end{array}$ & $\begin{array}{l}\text { Tsumura, C. and Otani, A. } \\
\text { (2009) The Challenge of } \\
\text { Elder Abuse: Detection, } \\
\text { Intervention and } \\
\text { Prevention. Chuohoki } \\
\text { Publishing, Tokyo. }\end{array}$ \\
\hline
\end{tabular}

Ito, K., Tada, M., Sakurai, C., Hara, M., Mizusawa, Y., Yamada, S., et al. (2013) Characteristics of Complex Cases of Community-Dwelling Elderly with Dementia: Relationship with Clinical Stage. Japanese Journal of Geriatric Psychiatry, 24, 1047-1061.

Ministry of Health, Labour and Welfare. Dealing with the Elder Abuse by Caregivers. http://www.mhlw.go.jp/topics/kaigo/bous hi/060424/dl/03.pdf

Matsuoka, K. and Shouno, S. (2011) Current Awareness of Domestic Elder Abuse Cases Conducted by Caregivers: Of Nurses Working at a Medical Facility in "A" Area. Journal of the Japan Academy for the Economic and Social Research Institute, Cabinet Office, Government of Japan. A Study on Self-Neglected Elders. http://www.esri.go.jp/jp/archive/hou/hou Prevention of Elder Abuse, 7, 64-71. 060/hou60 03.pdf

Tanida, E., Ohashi, C., Endou, A. and Takeshita, S. (2009) Recognition Change in Elder Abuse: Comparison before and after Old Age Nursing Practice. Journal of Okayama Research of Nursing Education, 33, 16-24.

Tanida, E. (2010) Recognition Group with Non-Recognition Group in the Abuse of Elderly was Compared about "Action on Dementia Elderly". Nursing Care Research, 9, 1-10.

Japan Yasuda, N. (2011) Limit and Problem about Psychological Abuse in Nursing Home: Through the Literature Review. Journal of Welfare Sociology, $\mathbf{6}$, 97-105.

Kishi, E., Yoshioka, S., Nojiri, Y., Mochizuki, Y., Konagaya, M., Hamazaki, Y., et al. (2011) Characteristics of Elderly Persons Living Alone in a State of Self-Neglect: Findings of National Survey Targeting Regional Integrated Support Centers. Bulletin of Department of Nursing, Faculty of Medical Technology, Teikyo University, 2, 1-21.

Kishi, E., Yoshioka, S., Nomura, S., Konagaya, M., Hamazaki, Y., Yonezawa, J., et al. (2011) Cases of Elder Self-Neglect Involving Specialists and their Counter-Measures: From Results of a Nationwide Survey with Regional Support Centers. Journal of the Japan Academy for the Prevention of Elder Abuse, 7, 125-138.

Konagaya, M., Kishi, E., Nomura, S., Yoshioka, S., Nojiri, Y., Mochizuki, Y., et al. (2013) Identifying the Factors Underlying Self-Neglect of the Elderly: From Self-Neglect Acknowledged by Professionals as Requiring Support. Journal of the Japan Academy for the Prevention of Elder Abuse, 9, 54-63.

Nomura, S. (2008) A Study on Self-Neglect Elders in the Community. Journal of the Japan Academy for the Prevention of Elder Abuse, 4, 58-75.

Liu, N., Ai X.Q., Cao, Y.P. and Zhang, Y.L. (2012) Understanding the Elder Abuse by Family Members. Journal of Central South University, 32, 419-423.

Du, X. and Sheng, J. (2014) The Current Research Situation of Elder Abuse. Chinese Journal of Gerontology, 5, 1432-1434. 


\section{Continued}

\begin{tabular}{|c|c|c|c|}
\hline \multirow{3}{*}{ China } & $\begin{array}{l}\text { Zhang, Y.X. and Zhang, J.P. (2012) Progress on Elder } \\
\text { Abuse. Journal of Traditional Chinese Medicine } \\
\text { University of Hunan, 32, 64-66. }\end{array}$ & & \\
\hline & $\begin{array}{l}\text { Wu, X.L. and Li, J. (2013) The Current Situation and } \\
\text { Cause of Elder Abuse. Population and Development, 19, } \\
\text { 85-91. }\end{array}$ & & \\
\hline & $\begin{array}{l}\text { Liu, S. (2013) The Current Phenomenon and } \\
\text { Countermeasure of "Elder Abuse". Social Scientist, 7, } \\
\text { 46-49. }\end{array}$ & & \\
\hline \multirow{5}{*}{ Other } & $\begin{array}{l}\text { Corbi, G., Grattagliano, I., } \\
\text { Ivshina, E., Ferrara, N., } \\
\text { Solimeno Cipriano, A. } \\
\text { and Campobasso, C.P. (2015) } \\
\text { Elderly Abuse: Risk Factors and } \\
\text { Nursing Role. Internal } \\
\text { and Emergency Medicine, 10, 297-303. }\end{array}$ & $\begin{array}{l}\text { National } \\
\text { Center } \\
\text { on Elder } \\
\text { Abuse. } \\
\text { Types of Abuse. } \\
\text { http://www.ncea.aoa.gov/FAQ/Type_Ab } \\
\underline{\text { use/index.aspx }}\end{array}$ & $\begin{array}{l}\text { Bonnie, R.J. and Wallace, } \\
\text { R.B. (2003) Elder } \\
\text { Mistreatment: Abuse, } \\
\text { Neglect, and Exploitation } \\
\text { in an Aging America. } \\
\text { National Academies Press, } \\
\text { Washington DC. }\end{array}$ \\
\hline & $\begin{array}{l}\text { Santos. C.M., De Marchi, R.J., Martins, A.B., Hugo, } \\
\text { F.N., Padilha, D.M. and Hilgert, J.B. (2013) The } \\
\text { Prevalence of Elder Abuse in the Porto Alegre } \\
\text { Metropolitan Area. Brazilian Oral Research, 27, } \\
\text { 197-202. }\end{array}$ & $\begin{array}{l}\text { Seniors } \\
\text { Rights } \\
\text { Victoria. } \\
\text { Your Rights. } \\
\text { http://seniorsrights.org.au/your-rights/ }\end{array}$ & \\
\hline & $\begin{array}{l}\text { Sooryanarayana, R., Choo, W.Y. and Hairi, N.N. (2013) } \\
\text { A Review on the Prevalence and Measurement of Elder } \\
\text { Abuse in the Community. Trauma Violence Abuse, 14, } \\
\text { 316-325. }\end{array}$ & $\begin{array}{l}\text { Elder Abuse } \\
\text { Prevention Unit. } \\
\text { Elder Abuse. } \\
\text { http://www.eapu.com.au/elder-abuse }\end{array}$ & \\
\hline & & $\begin{array}{l}\text { Action on Elder Abuse. What Is Elder } \\
\text { Abuse? } \\
\text { http://www.elderabuse.org.uk/Mainpages } \\
\text { /Abuse/abuse.html }\end{array}$ & \\
\hline & & $\begin{array}{l}\text { National Committee for the Prevention of } \\
\text { Elder Abuse. What Is Elder Abuse? } \\
\text { http://www.preventelderabuse.org/eldera } \\
\text { buse/ }\end{array}$ & \\
\hline
\end{tabular}

keep them quiescent were extracted and are represented in "restrained physically" and "restrained by improper usage of medicine". Moreover, "force-fed" was also extracted as an act of physical abuse.

Seven categories were extracted as acts of neglect. Four categories concerned food, clothing, and shelter of the elderly person: "provided with an inadequate/insufficient diet", "made to live in a poor environment", "left with a soiled body or dirty clothes", and "refused necessities such as clothing, eyeglasses, hearing aids". For medical care, "medical treatment is withheld" was extracted, and for the financial aspect, "refused financial support" was extracted. Additionally, acts such as the abandoning of an elder at a shopping center or other public location, or leaving him/her in an unsafe place or condition, were also seen as acts of neglect that were categorized as "abandoned outside his/her home".

For acts of psychological abuse, three categories that represented egregious verbal assaults or rejecting to respond to the elderly person were extracted, namely "subjected to a torrent of verbal abuse", "intentionally ignored", and "estranged from his/her family". In addition, categories related to acts that are significantly traumatic to the elderly person were extracted and named as follows: "insulted, ridiculed", "made to feel anxiety", "treated like a child", "humiliated in front of others", and "intimidated, threatened".

Concerning acts of sexual abuse, except for "inappropriately sexually touched without his/her consent", three sexual abuse acts were extracted that do not involve sexual contact with the elderly person: "forced to discuss sex-related topics", "forced to watch sexual images or videos", and "left undressed".

Three categories were extracted as acts of economic abuse: "assets are disposed of/used without his/her consent", "kept from managing/using his/her own assets", and "forced into issuing or changing the content of documents, such as power of attorney, will, deeds, or others”. 
Four categories were extracted related to the elderly person's food, clothing, and shelter: "doesn’t keep himself/herself clean", "lives in an inappropriate environment”, "neglects diet”, and "wears inappropriate clothing”. Self-neglect acts that involved the elderly person's health were extracted ("fails to seek necessary medical care") as well as social aspects of self-neglect ("doesn't interact with others"). Other aspects of self-neglect that were extracted include "can't properly use money or manage bank deposit records", and "disregards his/her surroundings or own belongings".

Table 2. Acts of elder abuse by subtype.

\begin{tabular}{|c|c|}
\hline Subtypes & Acts of elder abuse \\
\hline \multirow{4}{*}{ 1. Physical Abuse } & Subjected to physical violence (e.g., hitting, beating, punching) \\
\hline & Restrained physically \\
\hline & Restrained by improper dispensing of medicine \\
\hline & Force-fed \\
\hline \multirow{7}{*}{ 2. Neglect } & Provided with an inadequate/insufficient diet \\
\hline & Made to live in a poor environment \\
\hline & Left with a soiled body or dirty clothes \\
\hline & Refused necessities such as clothing, eyeglasses, hearing aids \\
\hline & Medical treatment is withheld \\
\hline & Refused financial support \\
\hline & Abandoned outside his/her home \\
\hline \multirow{8}{*}{ 3. Psychological Abuse } & Subjected to a torrent of verbal abuse (e.g., bellowing, cursing, saying something bad) \\
\hline & Intentionally ignored (e.g., not talking to the elderly, not having dinner with the elderly) \\
\hline & Estranged from his/her family \\
\hline & Insulted, ridiculed \\
\hline & Made to feel anxiety \\
\hline & Treated like a child \\
\hline & Humiliated in front of others \\
\hline & Intimidated, threatened \\
\hline \multirow{4}{*}{ 4. Sexual Abuse } & Inappropriately sexually touched without his/her consent \\
\hline & Forced to discuss sex-related topics \\
\hline & Forced to watch sexual images or videos \\
\hline & Left undressed \\
\hline \multirow{3}{*}{ 5. Economic Abuse } & Assets (e.g., savings, property) are disposed of/used without his/her consent \\
\hline & Kept from managing/using his/her own assets \\
\hline & Forced into issuing or changing the content of documents, such as power of attorney, will, deeds, or others \\
\hline \multirow{8}{*}{ 6. Self-Neglect } & Doesn’t keep himself/herself clean \\
\hline & Lives in an inappropriate environment \\
\hline & Neglects diet \\
\hline & Wears inappropriate clothing \\
\hline & Fails to seek necessary medical care \\
\hline & Doesn't interact with others \\
\hline & Can’t properly use money or manage bank deposit records \\
\hline & Disregards his/her surroundings or own belongings \\
\hline \multirow{4}{*}{ 7. Social Abuse } & Forbidden or restricted from contacting friends, relatives, and neighbors \\
\hline & Letters/phones are monitored or the elderly person’s communications are restricted \\
\hline & Monitored and restricted with regard to use of transportation \\
\hline & Restricted in access to health care facilities \\
\hline
\end{tabular}


With regard to social abuse, acts that cut off the elderly person's social contact with others were categorized as "forbidden or restricted from contacting friends, relatives, and neighbors" and "letters/phones are monitored or the elderly person's communications are restricted". In addition, two other categories were extracted: "monitored and restricted with regard to use of transportation" and "restricted in access to health care facilities".

\section{Discussion}

\subsection{Source of the Collected Materials}

In this review, although materials were extracted from Japan, China, and the West, it is clear that a much larger body of material was available from Japan and the West, perhaps because of the longer history of interest in elder abuse in those two areas. According to Sooryanarayana [11], elder abuse first came to light in the 1970s in the UK, and the United States pioneered research on elder abuse and neglect. Hence, as the leading experts in the study of elder abuse are in Western countries, a more extensive body of research about elder abuse has been published, and government and agencies have been established to devote themselves to prevention. In Japan, which can be viewed as a super-aged country, the government enforced the Elder Abuse Prevention Law in April 2006 in order to provide better social welfare to elderly persons and protect them from being abused. Japan carries out a nationwide survey every year to obtain data concerning the latest conditions of elder abuse, and moreover the Japan Academy for Prevention of Elder Abuse convenes every year to exchange the latest study outcomes concerning elder abuse. However, in contrast to Japan, although the elderly population is increasing in China as well, the Chinese people believe that elder abuse is not common. This may be due to their belief in strong family ties and the cultural values of filial piety, which encourages adults to love, respect, and take care of their parents [3]. Hence, elder abuse is not recognized as a social problem in China and few studies from China corroborate this fact. Elder abuse in China is likely to become increasingly serious in the future. Therefore, it is essential to increase awareness in China about the stern realities of elder abuse and recognize it as a social problem. Additionally, more extensive research on elder abuse in China will be needed.

\subsection{Acts of Elder Abuse}

Among the extracted acts of elder abuse, acts of physical abuse were relatively fewer than other subtypes of elder abuse, because physical abuse frequently leaves visible wounds, bruises, or broken bones [12] that make it easy to discover. On the contrary, psychological abuse is identified by observing the elderly person in an interaction [13] and is easily underestimated or neglected, because there is no clear evidence to assess it [13]. Therefore, it is important to extract acts of psychological abuse. In addition to the act of verbal abuse by the caregiver, which can be considered a typical act of psychological abuse, we also extracted acts such as "estranged from his/her family", "intimidated, threatened", etc., in order to obtain a comprehensive grasp of elder abuse in this review. In addition, because psychological abuse is much more complicated and potentially related to the psychological and mental situation of the elderly person, the repertory of acts of psychological abuse was more extensive than for physical abuse.

In China, sexual abuse has usually been included under physical abuse, because sexual abuse may cause some trauma to the body of the elderly person. However, in this review, some acts such as "forced to discuss sex-related topics", "forced to watch sexual images or videos", and "left undressed" were extracted. These were not just limited to acts in which the elderly person's body experiences trauma, by sexual touching without his/ her consent. Therefore, to include the sexual abuse acts under physical abuse is not appropriate. Moreover, unlike other types of elder abuse, sexual abuse is said to be the most hidden, and least acknowledged and reported form of elder abuse [14]. Thus, it is necessary to further study sexual abuse as an independent subtype in the future.

Economic abuse has been recently seen as the most prevalent type of elder abuse [15]. Research found that the prevalence of economic abuse was 5.2\% in the United States [16], 13.6\% in China [2], and 35.7\% in Japan [17]. Although economic abuse shows a high prevalence, Asian elders may show a high tolerance for such acts, as Asian traditional beliefs (rooted in Buddhism) call for disposing of their worldly goods in preparation for reincarnation [7]. Because of this traditional belief, it will be much harder to assess and support the elders who are economically abused. Nonetheless, it is important to identify acts of economic abuse so that they may be better understood. In this review, economic abuse refers to unduly obtaining property benefits from the elderly person. We studied this issue from two viewpoints: one was directly obtaining some benefits from the elderly 
person, by diverting the elderly person's money without his/her knowledge. The other was indirectly obtaining some benefits by not allowing the elderly person to manage his/her own assets while the caregiver has control. From those two viewpoints, we can say the acts of economic abuse have been comprehensively extracted.

In China and Japan, neglect was found to be one of the most common types of elder abuse [7]. In the US, research found that the one-year prevalence was 5.1\% for neglect, immediately following economic abuse [16]. Because the high prevalence of neglect is closely related to the life of the elderly person, in this review we organized and synthesized the acts of neglect from the perspective of food, clothing, shelter, medical care, etc. Moreover, extreme acts, like deserting or abandoning the elderly person, were also extracted and categorized as "abandoned outside his/her home." In addition, the act of "refused financial support” means although the caregiver has the financial ability, he/she does not economically support the elderly person who is in need. This is fundamentally different from economic abuse where the caregiver unjustly acquires a property benefit from an elderly person. As such, we could not recognize it as an act of economic abuse.

Apart from the generally recognized five subtypes of elder abuse, self-neglect and social abuse were also studied in the review as subtypes of elder abuse. Self-neglect refers to the elderly person neglecting himself/herself, by which the human rights of the elderly person are indeed compromised. According to Dong's research on the Chinese elderly living in the United States, the prevalence of self-neglect was $18.2 \%$ for mild self-neglect and $10.9 \%$ for moderate to severe self-neglect [18], showing a high prevalence. Therefore, it is indispensable to study self-neglect given the high prevalence as well as protection of human rights of the elderly. In this review, based on the definition of the self-neglect by Tsumura [10], we organized and synthesized the acts of self-neglect through four aspects: food, clothing, and shelter; medical care; individual hygiene; and social relations. The acts we extracted and categorized can exhaustively reflect the substance of acts of self-neglect in which the elderly neglect to take care of themselves in their daily life. People living in a society always have a tendency to try to socialize. As the elderly person has exerted his/her own ability to develop human relationships after years of social life, those relationships have now proven to have a significant influence on the elderly person's energy to live and sense of mental relief [19]. Social abuse by the caregiver, such as cutting off the elderly person's social contact with others, may cause feelings of loneliness or helplessness. Therefore, in order to obtain a comprehensive assessment of whether an elderly person is abused or not, we also need to assess social abuse and disclose its acts. However, few studies exist related to social abuse, and in this review, half of the acts of social abuse were extracted from the elder abuse prevention agencies. In the future, we should not only attempt to understand the current situation of social abuse through assessment, but will also need to study the influencing factors and carry out support measures for its prevention.

According to the ongoing literature review of elder abuse in Japan based on the Concentric Sphere Family Environment Theory [20] by the authors, preventive/inhibitory factors of elder abuse such as "psychological support of the whole family", "reducing the care burden of caregiver" within the family internal environment system and "providing a forum for information exchange" in the family external environment system could prevent, control or reduce the incidence rate of domestic elder abuse. In addition to the preventive/inhibitory factors of elder abuse, support measures such as "adjusting the relationships between caregiver and elderly", "multidisciplinary and multiagency cooperation" and "assisting the desired state of the family" could always be used to support the abused elderly person and his/her family in Japan. However, since the subtypes and the severity of elder abuse experienced by the elderly person may vary considerably, it is important to consider some prevention and support measures that would be in accord with different abusive experience involving each elderly person and his/her family. Therefore, future study needs to utilize this assessment tool to clarify prevention and support measures, in line with the subtypes and the severity of abuse undergone by the elderly person. Considering the instructions for utilization of this tool, we would intend to use it as a checklist in cases when medical professionals suspect a risk of elder abuse may exist, while simultaneously making clear its subtypes and severity. When evaluating the severity of elder abuse, the higher the severity, the greater the degree of urgency needed to support the elderly person. In this context, both medical professionals and elderly persons themselves may be users of this assessment tool. Nevertheless future study will still be needed to confirm the usage instructions and evaluate their effectiveness.

\subsection{Limitations}

Several limitations warrant attention in interpreting the findings from this review. First, although the descriptions about the acts of elder abuse in the collected materials were analyzed, some descriptions of the acts were 
just briefly described and the details were unknown. Therefore, it is difficult to assert that the abstraction levels of the categories are aligned. Second, the definition of social abuse used in this review was defined by means of integrating and organizing the extracted acts of social abuse. It cannot be treated as a strict definition. Future research should analyze the concept of social abuse through rigorous research methods. Third, although we extracted acts of elder abuse that can be seen as items of an assessment tool for identifying the presence and severity of elder abuse, such an assessment tool would need to be analyzed. Therefore, future research is needed to study the validity and reliability of the assessment tool.

\section{Conclusions}

To create the items of an assessment tool for domestic elder abuse, in addition to the five generally recognized subtypes of elder abuse (i.e., physical abuse, neglect, psychological abuse, sexual abuse, and economic abuse), two additional subtypes of elder abuse, self-neglect and social abuse, were added. When considering the protection of human rights of elderly persons, human relationships that the elderly person cultivated will have a significant influence on the elderly person's vitality and sense of mental relief. However, because of the insufficient recognition and ambiguities of what constitutes social abuse, further study of the concept of social abuse through rigorous research will be necessary.

Throughout this review, a total of 38 items were extracted as acts of elder abuse, broken down as follows: physical abuse (4 cases); neglect ( 7 cases); psychological abuse (8 cases); sexual abuse (4 cases); economic abuse (3 cases); self-neglect (8 cases); and social abuse (4 cases). Future research using these items will be needed in order to develop a reliable and valid assessment tool for domestic elder abuse.

\section{Acknowledgements}

This project was supported in part by a Grant-in-Aid for Scientific Research (B) from the Japan Society for the Promotion of Science (JSPS) in Japan (Grant No. 15H05084).

\section{Conflict of Interest Statement}

The authors declare no known conflicts of interest.

\section{References}

[1] Ministry of Health, Labour and Welfare (2015) Survey Results for Elder Abuse in 2013 Based on the Law of "Act on the Prevention of Elder Abuse, Support for Caregivers of Elderly Persons and Other Related Matters”. http://www.mhlw.go.jp/file/04-Houdouhappyou-12304500-Roukenkyoku-Ninchishougyakutaiboushitaisakusuishinshit su/0000073579.pdf

[2] Dong, X., Simon, M.A., Gorbien, M., Percak, J. and Golden, R. (2007) Loneliness in Older Chinese Adults: A Risk Factor for Elder Mistreatment. Journal of the American Geriatrics Society, 55, 1831-1835. http://dx.doi.org/10.1111/j.1532-5415.2007.01429.x

[3] Wu, L., Chen, H., Hu, Y., Xiang, H., Yu, X., Zhang, T., et al. (2012) Prevalence and Associated Factors of Elder Mistreatment in a Rural Community in People’s Republic of China: A Cross-Sectional Study. PLoS One, 7, e33857. http://dx.doi.org/10.1371/journal.pone.0033857

[4] Schofield, M.J., Reynolds, R., Mishra, G.D., Powers, J.R. and Dobson, A.J. (2002) Screening for Vulnerability to Abuse among Older Women: Women's Health Australia Study. Journal of Applied Gerontology, 21, 24-39. http://dx.doi.org/10.1177/0733464802021001002

[5] Fulmer, T., Street, S. and Carr, K. (1984) Abuse of the Elderly: Screening and Detection. Journal of Emergency Nursing, 10, 131-140.

[6] Umezaki, K. (2012) A Study on Elder Abuse by the Caregiver and Social Environment: Early Detection, Prevent towards the System of Family Support. Medical Social Work, 60, 18-26.

[7] Yan, E., Chan, K.L. and Tiwari, A. (2015) A Systematic Review of Prevalence and Risk Factors for Elder Abuse in Asia. Trauma Violence Abuse, 16, 199-219. http://dx.doi.org/10.1177/1524838014555033

[8] Reis, M. and Nahmiash, D. (1998) Validation of the Indicators of Abuse (IOA) Screen. Gerontologist, 38, 471-480. http://dx.doi.org/10.1093/geront/38.4.471

[9] Ministry of Justice (2006) Act on the Prevention of Elder Abuse, Support for Caregivers of Elderly Persons and Other Related Matters.http://www.japaneselawtranslation.go.jp/law/detail/?printID=\&id=2045\&re=01\&vm=02 
[10] Tsumura, C., Irie, Y., Hirota, A. and Okamoto, F. (2006) Problems about Self-Neglect of Elderly Persons. Osaka City University Journal of Nursing, 2, 1-10.

[11] Sooryanarayana, R., Choo, W.Y. and Hairi, N.N. (2013) A Review on the Prevalence and Measurement of Elder Abuse in the Community. Trauma Violence Abuse, 14, 316-325. http://dx.doi.org/10.1177/1524838013495963

[12] Wang, J.J. (2006) Psychological Abuse and Its Characteristic Correlates among Elderly Taiwanese. Archives of Gerontology and Geriatrics, 4, 307-318. http://dx.doi.org/10.1016/j.archger.2005.08.006

[13] Wang, J.J., Lin, J.N. and Lee, F.P. (2006) Psychologically Abusive Behavior by those Caring for the Elderly in a Domestic Context. Geriatric Nursing, 27, 284-291. http://dx.doi.org/10.1016/j.gerinurse.2006.08.016

[14] Malmedal, W., Iversen, M.H. and Kilvik, A. (2015) Sexual Abuse of Older Nursing Home Residents: A Literature Review. Nursing Research and Practice, 2015, Article ID: 902515. http://dx.doi.org/10.1155/2015/902515

[15] Harries, P., Davies, M., Gilhooly, K., Gilhooly, M. and Tomlinson, C. (2014) Educating Novice Practitioners to Detect Elder Financial Abuse: A Randomised Controlled Trial. BMC Medical Education, 14, 21. http://dx.doi.org/10.1186/1472-6920-14-21

[16] Acierno, R., Hernandez, M.A., Amstadter, A.B., Resnick, H.S., Steve, K., Muzzy, W., et al. (2010) Prevalence and Correlates of Emotional, Physical, Sexual, and Financial Abuse and Potential Neglect in the United States: The National Elder Mistreatment Study. American Journal of Public Health, 100, 292-297. http://dx.doi.org/10.2105/AJPH.2009.163089

[17] Anme, T. (2004) A Study of Elder Abuse and Risk Factors in Japanese Families: Focused on the Social Affiliation Model. Geriatrics and Gerontology International, 4, S262-S263. http://dx.doi.org/10.1111/j.1447-0594.2004.00221.x

[18] Dong, X.Q. (2014) Self-Neglect in an Elderly Community-Dwelling U.S. Chinese Population: Findings from the Population Study of Chinese Elderly in Chicago Study. Journal of the American Geriatrics Society, 62, 2391-2397. http://dx.doi.org/10.1111/jgs.13140

[19] Unuma, N. and Sekine, K. (2007) The Characteristics of a Son who Repeated Abuse and the Viewpoints of Prevention of Elderly Abuse: Based on the Elderly Abuse Survey to Home Helpers Participating in Training Sessions. Japanese Society for the Study of Social Welfare, 47, 111-123.

[20] Hohashi, N. and Honda, J. (2011) Development of the Concentric Sphere Family Environment Model and Companion Tools for Culturally Congruent Family Assessment. Journal of Transcultural Nursing, 22, 350-361. http://dx.doi.org/10.1177/1043659611414200 